\title{
ANEMTA FERROPRIVA EM PARTURIENTES E RECÉM-NASCIDOS
}

\author{
Sophia Cornbluth SZARFARC*
}

\begin{abstract}
RSPU-B/231
SZARFARC, S. C. - Anemia ferropriva em parturientes e recém-nascidos. Rev. Saúde públ., S. Paulo, 8:369-74, 1974.

Resumo: O objetivo proposto foi verificar a prevalência de deficiencia de ferro, num estrato de parturientes e recém-nascidos do municipio de são Paulo, de características sócio-económicas bem definidas. O levantamento bioquimico constituiu-se de dosagens de concentração de hemoglobina, hematócrito, ferro sérico e capacidade de ligação de ferro. Os resultados desse levantamento mostraram uma prevaléncia de 52,3\% de anemia em parturientes e de $21 \%$ de anemia em recém-nascidos. Concluiu-se que a ministração de sais de ferro, em serviços especializados de atendimento às gestantes pertencentes a classe sócio- economica semelhante à essa estudada, seria uma medida profilática que poderia diminuir essas porcentagens de anemia.
\end{abstract}

UNITERMos: Anemia ferropriva*; Gestantes*; Recém-nascidos*.

\section{N T R O D U A O}

Inúmeras são as referências feitas à anemia ferropriva em gestantes, destacando-a como um dos estados patológicos mais comuns na gravidez. A OMS ${ }^{13}$ assinala que a anemia influencia maleficamente a gravidez, afeta o desenvolvimento do feto e seu peso ao nascer e ainda contribui significativamente para o aumento da mortalidade perinatal. Ao mesmo tempo que SANCHEZ-MEDaL ${ }^{17}$ afirma que gestantes e crianças de até um ano se encontram no período mais crítico no que se refere à deficiência de ferro, a OMS ${ }^{13}$ ressalta a falta de dados informativos sobre o estado de nutrição materna e a incidência de anemia no recém-nascido.

Em nosso meio, são poucas as informações sobre valores hematológicos que se refiram à deficiência de ferro em gestantes e praticamente inexistentes as referências a valores hematológicos em recémnascidos. Como contribuição ao conhecimento da prevalência de deficiência de ferro, apresentamos os resultados obtidos nas determinações de hemoglobina, hematócrito, ferro sérico e capacidade de ligação de ferro em gestantes e recém-nascidos.

\section{MATERIAL E METODOS}

A população estudada constituiu-se de 263 parturientes a termo e 214 recém-nascidos atendidos na "Casa Maternal e de Assistência à Infância da Legião Brasileiras de Assistência". O sangue venoso

* Do Departamento de Nutrição da Faculdade de Saúde Pública da USP - Av. Dr. Arnaldo, 715 - São Paulo, SP - Brasil 
SZARFARC, S. C. - Anemia ferropriva em parturientes e recém-nascidos. Rev. Saúde públ., S. Paulo, 8:369-74, 1974 .

usado para as dosagens hematológicas foi obtido das gestantes durante o trabalho e o dos recém-nascidos, do cordão umbilical após a expulsão e antes da dequitação da placenta.

Cerca de $15 \mathrm{ml}$ de cada amostra de sangue foi colhido e dividido em duas partes: a primeira (cerca de $3 \mathrm{ml}$ ) recebida em frasco contendo anticoagulante, etileno diaminotetracetato de disódio (EDTA), foi utilizada para dosagens de hemoglobina e hematócrito; da 2 . $^{\text {. fração obte- }}$ ve-se soro para as dosagens de ferro sérico e capacidade de ligação de ferro.

A dosagem de hemoglobina foi feita pelo método da cianometahemoglobina, adotando-se o padrão artificial de VEN-
TURA et al. ${ }^{19}$. 0 volume corpuscular porcentual foi obtido centrifugando-se a amostra durante $5 \mathrm{~min}$ em tubos capilares. O método de Bothwell \& MaLLET ${ }^{4}$ adaptado para volumes semi-micro foi usado para dosagens do ferro sérico. A dosagem da capacidade de ligação de ferro foi feita pelo método de Schade et al. ${ }^{18}$ adaptado para pequenos volumes e modificado.

\section{R E S U L T D O S}

Os valores médios, desvios padrão e limites de confiança obtidos nas dosagens realizadas em parturientes e recém-nascidos encontram-se na Tabela 1.

TABELA 1

Valores médios, desvios padrăo e medianas de hemoglobina, hematócrito, ferro sérico e capacidade de ligação de ferro em parturientes e recém-nascidos

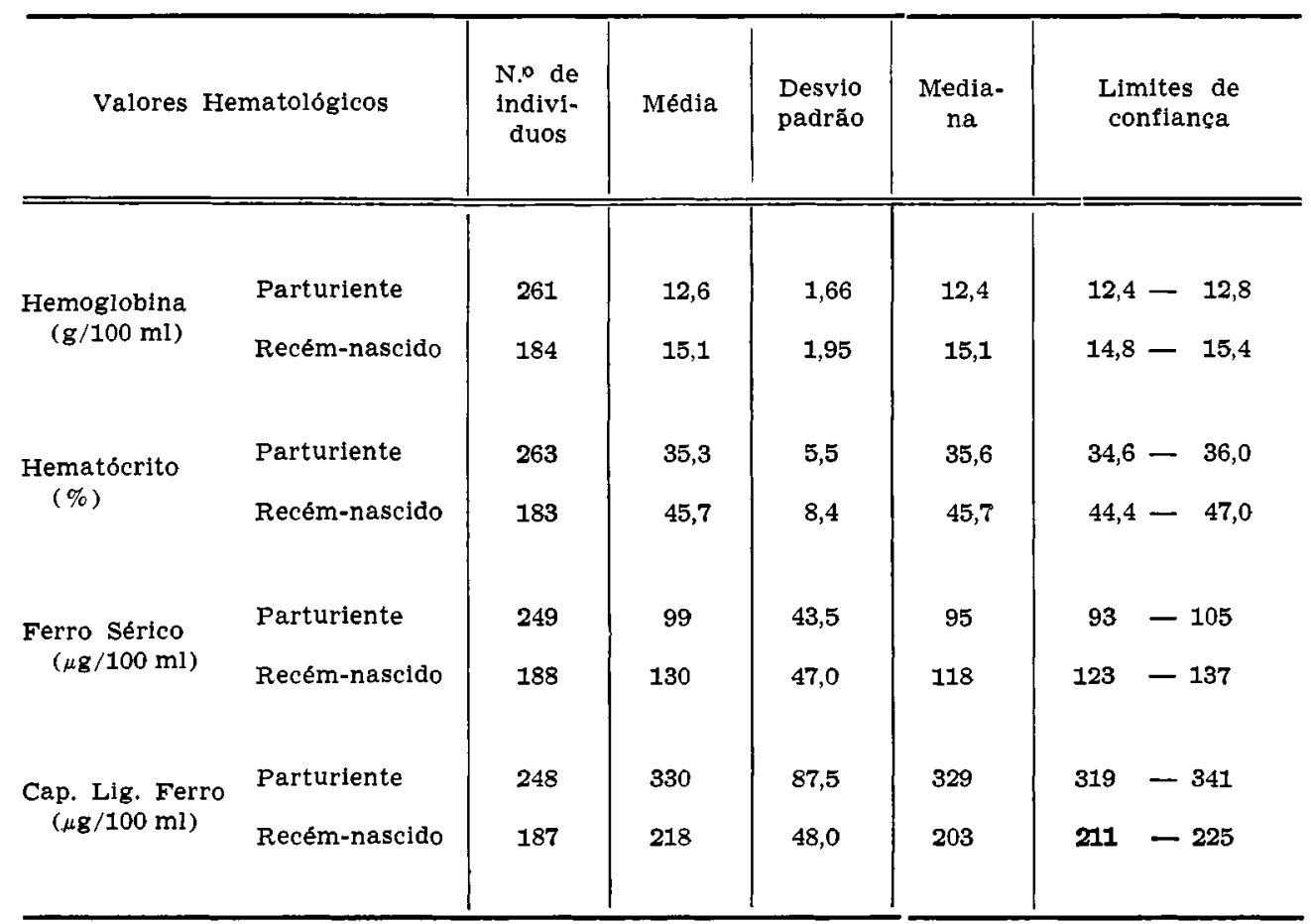

A distribuição de parturientes segundo a presença ou não de anemia na mãe encontra-se na Tabela 2; as Tabelas 3 e 4 informam a respeito da deficiência de ferro através de valores de ferro sérico e capacidade de ligação de ferro. A distribuição dos valores de hemoglobina em recém-nascidos encontra-se na Tabela 5 . 
SZARFARC, S. C. - Anemia ferropriva em parturientes e recém-nascidos. Rev. Saúde públ., S. Paulo, 8:369-74, 1974 .

TABEA 2

Distribuição de parturientes segundo a prevalência de anemia diagnosticada pelos valores de hemoglobina e hematócrito

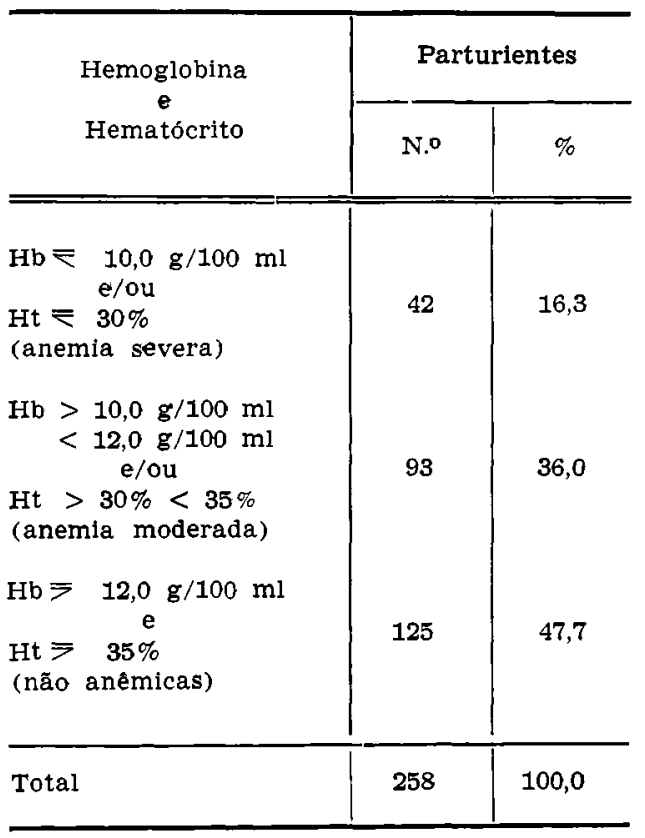

T A B E L A 3

Distribuição de parturientes segundo prevalência de deficiência de ferro diagnosticada pelos valores de ferro sérico

\begin{tabular}{|c|c|c|}
\hline \multirow{2}{*}{$\begin{array}{c}\text { Ferro Sérico } \\
\mu \mathrm{g} / 100 \mathrm{ml}\end{array}$} & \multicolumn{2}{|c|}{ Parturientes } \\
\hline & N.O & $\%$ \\
\hline $\begin{array}{c}\rightleftharpoons 70 \\
\text { (def. severa) }\end{array}$ & 41 & 15,7 \\
\hline $\begin{array}{l}>70<90 \\
\text { (def. moderada) }\end{array}$ & 62 & 23,8 \\
\hline$\underset{\text { (normal) }}{>} 90$ & 157 & 60,5 \\
\hline Total & 260 & 100,0 \\
\hline
\end{tabular}

TA B E L A 4

Distribuição de parturientes segundo valores de capacidade de ligação de ferro

\begin{tabular}{c|r|r}
\hline $\begin{array}{c}\text { Capacidade de ligação } \\
\text { de ferro } \\
(\mu \mathrm{g} / 100 \mathrm{ml})\end{array}$ & \multicolumn{2}{|c}{ Parturientes } \\
\cline { 2 - 3 } & N.o & $\%$ \\
\hline \hline 260 & 45 & 17,6 \\
$>260 ₹ 360$ & 135 & $\mathbf{5 2 , 2}$ \\
$>360$ & 78 & $\mathbf{3 0 , 2}$ \\
\hline Total & $\mathbf{2 5 8}$ & $\mathbf{1 0 0 , 0}$ \\
\hline
\end{tabular}

TABELA 5

Distribuição dos recém-nascidos segundo valores de hemoglobina

\begin{tabular}{c|c|c}
\hline & \multicolumn{2}{|c}{ Recém-nascidos } \\
\cline { 2 - 3 }$(\mathrm{g} / 100 \mathrm{ml})$ & N.0 & $\%$ \\
\hline $9,0-10,5$ & 4 & 1,8 \\
$10,5-1-12,0$ & 13 & 6,1 \\
$12,0-1-13,5$ & 28 & 13,1 \\
\hline $13,5 \mid-15,0$ & 56 & 26,0 \\
$15,0 \mid-16,5$ & 69 & 32,0 \\
$16,5-1-18,0$ & 30 & 14,0 \\
$18,0-23,5$ & 15 & 7,0 \\
\hline Total & 215 & 100,0 \\
\hline
\end{tabular}

COMENTARIOS

As concentrações de hemoglobina e hematócrito são os índices mais usados na verificação da presença de anemia. Os critérios de limites de normalidade não são homogêneos nem sempre permitindo comparação dos resultados obtidos. A escolha dos limites de normalidade por 
SZARFARC, S. C. - Anemia ferropriva em parturientes e recém-nascidos. Rev. Saúde públ., S. Paulo, 8:369-74, 1974.

nós adotada, superiores aos fixados pela $\mathrm{OMS}^{14}$, baseou-se nas afirmações de BENJamin ${ }^{3}$, Rauramo et al. ${ }^{16}$ e de Sanchez-MEDAL ${ }^{17}$ que os valores $12,0 \mathrm{~g} / 100 \mathrm{ml}$ de hemoglobina e $35 \%$ de hematócrito são mais adequados para distinguir gestantes anêmicas das não anêmicas. Acresce que nossa amostra é constituída de parturientes a termo para as quais RACHMILEVITZ ${ }^{15}$ e Almeida et al. ${ }^{1}$ observaram valor médio de hemoglobina mais elevado quando comparado com outros períodos de gestação.

A prevalência de $52,3 \%$ de anemia da qual $16,3 \%$ são de anemia severa (Tabela 2) é extremamente elevada, especialmente se considerarmos que esse valor pode ser inferido para $10 \%$ da população da cidade de São Paulo, uma vez que a Legião Brasileira de Assistência atende, ao redor dessa porcentagem, todos os nascimentos vivos ocorridos na cidade de São Paulo.

A concentração de ferro sérico reflete a reserva marcial de ferro. É essa reserva a garantia de uma eritropoiese adequada em estados fisiológicos de maior demanda como é a gravidez.

As médias obtidas por Lima ${ }^{10}$, em sub-amostra de puérperas atendidas também pela Legião Brasileira de Assistência, para concentração de hemoglobina e hematócrito $(10,42 \mathrm{~g} / 100 \mathrm{ml}$ de $\mathrm{Hb}$ e $31,31 \%$ de $\mathrm{Ht}$ ) foram significativamente inferiores às obtidas em nossa amostra $(12,6$ $\mathrm{g} / 100 \mathrm{ml}$ de $\mathrm{Hb}$ e $35,3 \%$ de $\mathrm{Ht}-\mathrm{Ta}-$ bela 1). Essa diferença talvez possa ser explicada pelo fato de Lima ${ }^{10}$ ter excluído de sua amostra aquelas que receberam suplementação de ferro e ainda de fazer parte de sua população $59 \%$ de puérperas com alterações medulares, as quais estão freqüentemente associadas à presença de anemia ferropriva. No que se refere a ferro sérico, o valor obtido por Lima ${ }^{10}(97$ $\mu \mathrm{g} / 100 \mathrm{ml}$ ) está bem próximo do valor médio obtido por nós $(99 \mu \mathrm{g} / 100 \mathrm{ml})$.
Tem sido observado que a capacidade de ligação de ferro aumenta com o desenrolar da gravidez, não estando esse aumento relacionado à variação de concentração de ferro sérico *. Foi verificado entre 56 gestantes residentes em Apiaí e Ribeira que o valor médio de ferro sérico foi $98 \pm 25 \mu \mathrm{g} / 100 \mathrm{ml}$, valor este estatisticamente igual ao obtido para as mulheres em idade reprodutiva das mesmas localidades e também igual ao obtido para as parturientes da Legiāo Brasileira de Assistência. No entanto, o valor da capacidade de ligação de ferro entre as mulheres não gestantes de Apiaí e Ribeira foi $249 \pm 54 \mu \mathrm{g} / 100 \mathrm{ml}$, valor esse significativamente menor do que o valor médio obtido para as gestantes da mesma região $(280 \pm 63 \mu \mathrm{g} / 100 \mathrm{ml})$ e obtido para as parturientes amostradas (330 \pm $87 \mu \mathrm{g} / 100 \mathrm{ml}$ ).

Considerando como limite de normalidade para ferro sérico o valor $90 \mu \mathrm{g} / 100$ $\mathrm{ml}$ sugerido por HERBERT ${ }^{7}$, verificamos que $39,5 \%$ da nossa população tem deficiência de ferro (Tabela 3). Quanto à capacidade de ligaçāo de ferro, $30 \%$ das gestantes examinadas têm valores acima do limite adotado como máximo adequado $(360 \mu \mathrm{g} / 100 \mathrm{ml})$ segundo sugestão de Herbert $^{7}$ (Tabela 4).

Como já citamos, há poucas referências a valores hematológicos de recém-nascidos. A média obtida para concentração de hemoglobina $(15,1 \mathrm{~g} / 100 \mathrm{ml}-$ Tabela 1) foi mais baixa do que a obtida por outros autores. LANzKowsKI 8,2 obteve em 3 populações as médias 19,8, 18,9 e $19,3 \mathrm{~g} / 100 \mathrm{ml}$; Chowdhuri et al. ${ }^{5}$ obtiveram a média $16,8 \mathrm{~g} / 100 \mathrm{ml}$; BAGCHI \& BosE ${ }^{2}$ encontraram os valores 17,3 e $16,9 \mathrm{~g} / 100 \mathrm{ml}$; LORIA et al. ${ }^{11}$, o valor $16,3 \mathrm{~g} / 100 \mathrm{ml}$ e ainda GRUNSEIT et al. ${ }^{6}$ obtiveram o valor $20,7 \pm 3,1 \mathrm{~g} /$ $100 \mathrm{ml}$. No entanto, a importância do valor de hemoglobina é ressaltada por Molisson \& CuTbush ${ }^{12}$ que referem uma

* Dados obtidos em Apiaí e Ribeira - trabalho em andamento por S. C. Szarfarc e M. J. Roncada. 
SZARFARC, S. C. - Anemia ferropriva em partur entes e recém-nascidos. Rev. Saúde públ., S. Paulo, 8:369-74, 1974 .

evidente relação positiva entre o valor de hemoglobina da criança ao nascer e sobrevida dessa criança. Considerando como esses autores, $13,6 \mathrm{~g} / 100 \mathrm{ml}$ como limite mínimo de normalidade de $\mathrm{Hb}$, $21 \%$ dos recém-nascidos são anêmicos (Tabela 5). É interessante observar que a porcentagem de presença de anemia em parturientes é muito superior à porcentagem em recém-nascidos, significando, possivelmente, uma espoliação da mãe.

Os resultados obtidos por LoRI et al. ${ }^{11}$ em recém-nascidos apresentam o valor médio de ferro sérico maior e de capacidade de ligação de ferro menor do que os obtidos por nós. Não sabemos a que atribuir essa diferença, uma vez que as populações estudadas foram semelhantes e que os valores obtidos nas dosagens em sangue das parturientes por aqueles autores foram bastante parecidos aos nossos. Diga-se, entretanto, que não encontramos mais referências à concentração de ferro sérico e à capacidade de ligação de ferro para recém-nascidos, que permitissem uma interpretação mais acurada.

Os resultados obtidos nas análises bioquímicas especialmente no que se refere à hemoglobina e ao hematócrito das gestantes evidenciam a necessidade de um programa de suplementação de ferro às gestantes, de tal forma a diminuir a prevalência dessa deficiência.

\section{CONCLUSOES}

$\mathrm{Da}$ análise dos índices hematológicos que expressam prevalência de anemia ferropriva em parturientes e recém-nascidos, resultam as seguintes conclusões:

1. o estudo feito em amostra estratificada de parturientes assistidas pela Legião Brasileira de Assistência revelou grande prevalência de anemia; $52,3 \%$ das examinadas eram anêmicas, sendo $16.3 \%$ severamente anêmicas e $36,0 \%$ moderamente anêmicas;

2. com relação a estoques férricos, $45 \%$ das gestantes têm valores de ferro sérico abaixo do valor normal $(90 \mu \mathrm{g} /$ $100 \mathrm{ml}$ de soro);

3. $30 \%$ das mulheres examinadas têm maior capacidade de ligação de ferro do que o limite adotado como normal $(360 \mu \mathrm{g} / 100 \mathrm{ml}$ de soro );

4. $21 \%$ dos recém-nascidos foram considerados anêmicos, segundo o critério fornecido pela literatura $(13,6$ $\mathrm{g} \mathrm{Hb} / 100 \mathrm{ml}$ );

5. há necessidade de fornecimento de ferro suplementar às gestantes atendidas pela Legião Brasileira de Assistência, o que iria atender às gestantes e prevenir, possivelmente, a anemia em recém-nascidos.

RSPU-B/231

Szarfarc, S. C. - [Hematological study of pregnant women and newborn children.] Rev. Saúde públ., S. Paulo, 8:369-74, 1974.

SumMary: The present paper was planned to study prevalence of iron deficiency in a group of women at delivery and newborn children of comparable social and economic status. The biochemical survey included hemoglobin concentration, packed cell volume, serum iron and iron binding capacity. The results showed a prevalence of anemia of $52,3 \%$ for the women and $21,0 \%$ for the newborn. Iron administration, at specialized services would be a sound prophylactic measure.

UNITERmos: Iron deficiency*; Hematological study*; Pregnancy women*; Newborn children. 
SZARFARC, S. C. - Anemia ferropriva em parturientes e recém-nascidos. Rev. Saúde públ., S. Paulo, 8:369-74, 1974 .

\section{REFERENCIAS BIBLIOGRÁFICAS}

1. ALMEIDA, P.A.M. et al. - Curva de hemogiobina em um grupo de gestantes normais. Rev. Saúde públ., S. Paulo, 7:273-82, 1973.

2. BAGCHI, K. \& BOSE, A.K. - Effect of low nutrient intake during pregnancy on obstetrical performance and offspring. Amer. J. clin. Nutr., 11:586-92, 1962.

3. BENJAMIN, F. et al. - Serum levels of folic acid, vitamin $B_{12}$ and iron in anemia of pregnancy. Amer. $J$. Obstet. Gynec., 96:310-5, 1966.

4. BOTHWELL, T.H. \& MALLET, B. The determination of iron in plasma or serum. Biochem. J., 59:599$602,1955$.

5. CHOWDHURY, S. et al. - Comparative hematological studies of iron and phosphorus blood levels in mother and newborn. Amer. J. Obstet. Gynec., 87:540-2, 1963.

6. GRUNSEIT, F. et al. - Hemoglobin levels in low birth weight babies receiving iron supplements. Med. $J$. Austr., 58:79-82, 1971.

7. HERBERT, V. - Drugs effective in iron deficiency and other hypochromic anemias. In: GOODMAN, L.S. \& GİLMAN, A., ed. Pharmacological basis of therapeutics. 3rd. ed. New York, MacMillan, 1965. p. 1394-442.

8. LANZKOWSKY, P. - The effect of intramuscular iron dextran complex administered to women during pregnancy on their hematological values and on hemoglobin levels of their infants. $J$, Obstet. Gynaec. Brit. Emp., 68:52-61, 1961.

9. LANZKOWSKY, P. - Influence of maternal iron deficiency anaemia on the hemoglobin of the infant. Arch. Dis. Child., 36:205-9, 1961.

10. LIMA, G.R. - Contribuição para o estudo dos estados folicóprivos no puerpério. São Paulo, 1968. [Tese - Escola Paulista de Medicina].
11. LORIA, A. et al. - Comparación entre el estado nutricional de la madre $y$ del recién nascido. Gac. med. Mex., 99:229-39, 1969 .

12. MOLLISON, P.L. \& CUTBUSH, M. - A method of measuring the severity of a series of cases of hemolityc disease of the newborn. Blood, 6: $777-88,1951$.

13. ORGANIZAÇAO MUNDIAL DA SAUUE. Expert Committee on the Prevention of Perinatal Mortality and Morbidity, Geneva, 1969. Report, Geneva, 1970. (Techn. Rep. Ser., 457).

14. ORGANIZAÇAO MUNDIAL DA SAÚDE. Grupo Cientifico sobre Anemias Nutricionales. Ginebra, 1967. Informe. Ginebra, 1968 (Ser. Inf. techn., 405).

15. RACHMILEVITZ, M. et al. - Anemia of pregnancy in a rural community of upper Galilee. Israel J. med. Sci., 2:472-9, 1966 .

16. RAURAMO, L. et al. - Serum folic acid content in pregnancy. Acta obstet. Gynec. scand., 46(Suppl. $\left.7^{\prime}\right): 101-2$, 1967.

17. SANCHEZ-MEDAL, L. - Iron deficiency in pregnancy and infancy. In: SYMPOSIUM ON IRON METABOLISM AND ANEMIA. Washington, D.C., 1969. Abstracts of papers. Washington, D.C., PAHO, 1969. p. 9.

18. SCHADE, A.L. et al. - Bound iron and unsaturated iron binding capacity of serum; rapid and reliable quantitative determination. Proc. Soc. exp. Biol., N.Y., 87:443-8, 1954.

19. VENTURA, F. et al. - Hemoglobina: dosagem pelo método da cianometahemoglobina. Uso de solução artíficial para calibração dos aparelhos colorimétricos. Rev. Hosp. Clin. Fac. Med., S. Paulo, 22:303-4, 1967.

Recebido para publicação em 9/ 9/1974 Aprovado para publicacão em 4/10/1974 